\title{
PA-152 THE EFFECT OF HELMINTH CO-INFECTION ON MALARIA-SPECIFIC IMMUNOGLOBULIN G RESPONSES
}

Clarisse Njua-Yafi, ${ }^{1}$ Theresa Nkuo-Akenji, ${ }^{2}$ Judith Anchang-Kimbi, ${ }^{2}$ Tobias Apinjoh, ${ }^{2}$ Regina Mugri, ${ }^{2}$ Hanesh Chi, ${ }^{2}$ Rolland Tata, ${ }^{2}$ Charles Njumkeng, ${ }^{2}$ Daniel Dodoo, ${ }^{3}$ Michael Theisen, ${ }^{4}$ Eric Achidi ${ }^{2}$. 'University of Yaoundé I, Cameroon; ${ }^{2}$ University of Buea, Cameroon; ${ }^{3}$ NMIMR, Ghana; ${ }^{4}$ SSI, Denmark

\subsection{6/bmjgh-2016-000260.178}

Background Malaria and helminthiases overlap extensively in their epidemiological distributions, and co-infections are common. Helminth infection has a profound effect on the immune system such as the induction of immuno-regulatory mechanisms such as potent regulatory $\mathrm{T}$ cell responses known to suppress cellular effector mechanisms.

Methods The prevalence of malaria parasitaemia, intestinal helminths, co-infection and anaemia was determined in a crosssectional study (March 2011) of 372 children aged 6 months to 10 years resident in Mutengene in south-western Cameroon. Plasma total IgG and IgG1-4 subclass antibody levels to $P$. falciparum apical membrane antigen 1 (AMA1), the $\mathrm{N}$-terminal nonrepeat region (GLURP R0) and the C-terminal repeat region of glutamate rich protein (GLURP R2) and merozoite surface protein 3 (MSP3) were measured by standardised ELISA.

Results Prevalence was as follows: malaria parasitaemia (mp) $18 \%$, pyrexia $25.4 \%$, helminths $19.7 \%$, and anaemia $71.5 \%$. Amongst those who were mp-positive, $25.4 \%$ were symptomatic (4.5\% overall). Almost all helminth infections were the soiltransmitted helminths Ascaris, Trichuris and hookworm (96.4\%) with a few cases of Hymenolepis and Enterobius. Haemoglobin concentration $(\mathrm{g} / \mathrm{dl})$ correlated positively with age and negatively with $\mathrm{mp}$ density $(\mathrm{p} \leq 0.001)$. The mean haemoglobin $(\mathrm{g} / \mathrm{dl})$ level of participants co-infected with both parasites (3.4\%) was higher compared to participants infected with either Plasmodium $(15.8 \%)$ or helminths $(16.1 \%)$ alone $(p<0.01)$. IgG and IgG1-4 subclass antibody levels to all recombinant antigens correlated positively with age $(\mathrm{p}<0.01)$. Total $\operatorname{IgG}, \operatorname{IgG} 1,2 \& 3$ levels to all the antigens tested were significantly (except MSP3 IgG2, $\mathrm{p}=0.08$ ) higher in participants infected with Plasmodium alone, compared to the co-infection, helminths only and no infection groups. Decreased levels of AMA1 IgG associated significantly with co-infection $(\mathrm{OR}=0.27,95 \% \mathrm{CI}: 0.11-0.68)$. Increased MSP3 IgG and IgG1-4 levels were significantly associated with children infected with Plasmodium alone compared to children co-infected with both parasites.

Conclusions Infection with intestinal helminths stifles protective anti-plasmodial antibody responses. 